\title{
Ocular blood flow velocities in patients with proliferative diabetic retinopathy and healthy volunteers: a prospective study
}

\author{
Antonio Mendívil, Victoria Cuartero, María Paz Mendívil
}

\begin{abstract}
Background-Diabetes affects the vascular ocular circulation. Colour Doppler imaging allows for simultaneous two dimensional anatomical imaging and Doppler evaluation of blood flow velocity; with this technique ocular blood flow velocity can be evaluated in normal and diabetic patients.

Methods-A prospective study compared blood flow velocity in ocular vessels (ophthalmic artery, posterior ciliary arteries, central retinal vessels, and vortex veins) of 25 patients with proliferative diabetic retinopathy and 30 age matched normal subjects using a colour Doppler imaging unit (Toshiba Sonolayer SSA-270 A with a 5.0 MHz PLF-503 ST phased array scanning head).

Results-The diabetic patients had lower blood velocities than the volunteers. There were significant differences in ophthalmic artery; systolic $(p<0.01)$, diastolic $(p<0 \cdot 001)$, mean velocity $(p<0.05)$, and central retinal artery; systolic $(p<0.001)$, diastolic $(\mathbf{p}<0.001)$, mean velocity $(p<0 \cdot 05)$. No significant correlations were found between age and blood velocities. Conclusion-Ocular blood flow velocity was decreased in diabetic patients with proliferative diabetic retinopathy.

(Brf Ophthalmol 1995; 79: 413-416)
\end{abstract}

Although diabetic microangiopathy has its greatest clinical effects in the retina and kidney, there is much evidence that the process is generalised, involving most capillary beds.

Most patients with diabetes mellitus develop characteristic abnormalities of retinal blood vessels and blood rheology. These abnormalities seem to alter retinal blood flow. The earliest detectable morphological changes in diabetic retinopathy are microaneurysms and capillary closure. Despite intensive research efforts, the pathogenic mechanisms important to the initiation and progression of diabetic retinopathy are still poorly understood. It is clear that whatever humoral factors influence the microcirculation it remains to be explained why it is the retina that develops capillary occlusion, exudates, microaneurysms, haemorrhages, and new vessel formation whereas other microcirculations do not. Diabetes predominantly affects the ocular microcirculation and, apart from some minor dilatation of the retinal arterioles and venules, no changes are seen in the major vessels in the early stages. ${ }^{1}$ Most observers agree that a plausible pathogenetic explanation for proliferation of vascular endothelial cells in proliferative diabetic retinopathy (PDR) is ischaemia of the inner retinal layers secondary to closure of parts of the retinal capillary bed. ${ }^{2}$

Colour Doppler imaging (CDI) allows for simultaneous two dimensional anatomical imaging and evaluation of blood flow velocity. ${ }^{3}$

In this report, we study ocular blood flow velocities in patients with PDR and healthy volunteers.

\section{Patients and methods}

A total of 25 diabetic patients (13 women and 12 men) whose ages ranged from 28 to 65 years (mean 58 (SD 15) years) were included in this prospective study. These patients were diagnosed as having PDR (all the eyes in study met the Severe Early Treatment Diabetic Retinopathy Study (ETDRS) criteria and were candidates for photocoagulation. ${ }^{4}$ Sixteen diabetics were insulin dependent and nine were non-insulin dependent; none of them had been photocoagulated. Patients had no relevant medical or ophthalmic history, except for their diabetes. The results obtained from diabetics were compared with those of an age matched control group of apparently healthy volunteers. The characteristics of the diabetic and the normal subjects are summarised in Table 1. No significant difference between the groups was found with respect age, intraocular pressure, and systolic and diastolic blood pressure. In addition, three volunteers were excluded because of technique difficulties (unclear definition of spectral display).

The Toshiba Sonolayer SSA-270 A colour Doppler unit was used in this study, with a 5.0 MHz PLF-503 ST phased array scanning head. All procedures were performed by the authors. Ophthalmic artery (OA), central retinal artery (CRA), central retinal vein $(\mathrm{CRV})$, vortex veins $(\mathrm{VV})$, and posterior ciliary arteries (PCA), systolic, mean arterial blood flow, and end diastolic velocities were

Table 1 Characteristics of diabetics and normal subjects. (Mean (SD))

\begin{tabular}{lcc}
\hline & $\begin{array}{l}\text { Diabetics } \\
(n=25)\end{array}$ & $\begin{array}{c}\text { Normals } \\
(n=30)\end{array}$ \\
\hline Sex M/F & $12 / 13$ & $14 / 16$ \\
Age (years) & $58(15)$ & $56(13)$ \\
Insulin/non-insulin dependent & $16 / 9$ & - \\
Systolic blood pressure (mm Hg) & $128(25)$ & $115(20)$ \\
Diastolic blood pressure (mm Hg) $_{\text {HbA }_{1 \mathrm{c}} \text { (g/dl) }}^{82(12)}$ & $80(9)$ \\
Intraocular pressure & $7 \cdot 3(1 \cdot 9)$ & - \\
\hline
\end{tabular}


Table 2 Maximum systolic blood flow velocity in healthy volunteers $(n=30)$ and diabetic patients with proliferative diabetic retinopathy $(n=25)$

\begin{tabular}{|c|c|c|c|}
\hline Vessel & $\begin{array}{l}\text { Normals }(S D) \\
\text { systolic }(\mathrm{cm} / \mathrm{s}) \\
\text { (range) }\end{array}$ & $\begin{array}{l}\text { Diabetics }(S D) \\
\text { systolic }(\mathrm{cm} / \mathrm{s}) \\
\text { (range) }\end{array}$ & p Value \\
\hline $\begin{array}{l}\text { A } \\
\text { CA } \\
R A \\
\text { RV } \\
\text { V }\end{array}$ & $\begin{array}{c}36.6(7 \cdot 0)(29-47) \\
14 \cdot 2(2 \cdot 7)(9-19) \\
12.6(2 \cdot 6)(9-16) \\
4.42(0.51)(4-5) \\
5.54(1.1)(5-8)\end{array}$ & $\begin{array}{c}31 \cdot 7(6 \cdot 7)(24-45) \\
13 \cdot 4(1 \cdot 8)(9-16) \\
9 \cdot 64(1 \cdot 8)(7-13) \\
5 \cdot 24(2 \cdot 4)(3-11) \\
5 \cdot 12(1 \cdot 5)(3-9)\end{array}$ & $\begin{array}{l}<0.01 \\
<0 \cdot 1 \\
<0.001 \\
<0.1 \\
\quad \text { NO }\end{array}$ \\
\hline
\end{tabular}

$\mathrm{OA}=$ ophthalmic artery; $\mathrm{PCA}=$ posterior ciliary arteries; $C R A=$ central retinal artery; $C R V=$ central retinal vein; $\mathrm{VV}=$ vortex veins

measured in patients and volunteers. The 55 eyes studied, chosen at random between both eyes when it was possible, showed a graphic representation of Doppler information that was acceptable (pulsatile flow in arteries and continuous flow in veins). Colour Doppler was used first to provide a survey of the area of interest and identify appropriate blood vessels. Once optimally visualised by colour flow, specific ocular vessels could then be rapidly examined in pulsed Doppler. When spectral analysis was performed, the estimated in situ peak temporal average (SPTA) intensity was approximately $70 \mathrm{~mW} / \mathrm{cm}^{2}$, which fell well below the safety limit established by the American Institute of Ultrasound in Medicine. The variable suggested is $100 \mathrm{~mW} / \mathrm{cm}^{2}$. The measuring technique used is presented in detail elsewhere. ${ }^{5}$

It is well known from several studies that hypertension is a significant risk factor for the incidence and progression of diabetic retinopathy studies. In hypertensive patients, higher blood pressure was associated with increased volume flow in the patients studied at different times. For this reason, blood pressure was recorded in each group. We excluded this factor because only patients with systolic pressure below. $140 \mathrm{~mm} \mathrm{Hg}$ and diastolic blood pressure below $90 \mathrm{~mm} \mathrm{Hg}$ were evaluated. In this study, all diabetics with glycosylated haemoglobin $\left(\mathrm{HbA}_{1 \mathrm{c}}\right)>9.5 \mathrm{~g} / \mathrm{dl}$ were excluded. Then, subjects with bad glycaemic control were rejected. This factor worsens the retinal microcirculation and would have influenced the results obtained.

The research followed the tenets of the Declaration of Helsinki and informed consent was obtained.

Means and standard deviation are given for all samples.

The statistical method used for comparing

Table 3 Maximum diastolic blood flow velocity in healthy volunteers $(n=30)$ and diabetic patients with proliferative diabetic retinopathy $(n=25)$

\begin{tabular}{lllc}
\hline Vessel & $\begin{array}{l}\text { Normal }(S D) \\
\text { diastolic }(\mathrm{cm} / \mathrm{s}) \\
\text { (range) }\end{array}$ & $\begin{array}{l}\text { Diabetic }(S D) \\
\text { diastolic }(\mathrm{cm} / \mathrm{s}) \\
\text { (range) }\end{array}$ & p Value \\
\hline OA & $10 \cdot 8(4 \cdot 4)(6-20)$ & $5.96(3.0)(3-13)$ & $<0.001$ \\
PCA & $4 \cdot 8(1.9)(4-8)$ & $4 \cdot 00(0.58)(3-5)$ & $<0.05$ \\
CRA & $4 \cdot 10(0 \cdot 80)(3-5)$ & $3.20(0.65)(2-4)$ & $<0.001$ \\
CRV & $2 \cdot 65(0.50)(2-3)$ & $2 \cdot 72(0.74)(2-4)$ & NO \\
VV & $3.64(0.88)(2-5)$ & $3.12(0.78)(2-5)$ & $<0.05$
\end{tabular}

$\mathrm{OA}=$ ophthalmic artery; $\mathbf{P C A}=$ posterior ciliary arteries; $\mathrm{CRA}=$ central retinal artery; $\mathrm{CRV}=$ central retinal vein; CRA = central retinal
$\mathrm{VV}=$ vortex veins.
Table 4 Mean arterial blood flow velocities in healthy volunteers $(n=30)$ and diabetic patients with proliferative diabetic retinopathy $(n=25)$. Both measurements in $\mathrm{cm} / \mathrm{s}$

\begin{tabular}{lccc}
\hline Vessel & Normal (SD) & Diabetic (SD) & p Value \\
\hline OA & $23.7(7 \cdot 8)$ & $16.6(5 \cdot 8)$ & $<0.05$ \\
PCA & $9.57(2 \cdot 6)$ & $7.2(1.4)$ & $<0.05$ \\
CRA & $7.35(2 \cdot 7)$ & $5.42(1 \cdot 6)$ & $<0.05$ \\
\hline
\end{tabular}

$\mathrm{OA}=$ ophthalmic artery; $\mathrm{PCA}=$ posterior ciliary arteries; $\mathrm{CRA}=$ central retinal artery.

the groups was Student's $t$ test for unpaired samples. In order to exclude interindividual variability as a factor in pooled data comparisons, we also performed non-parametric comparison using the Mann Whitney technique. p Values of $<0.05$ were considered significant.

\section{Results}

Fifty-five eyes of 55 individuals were studied. The data of systolic and diastolic peak velocities in healthy volunteers are similar to those previously reported. 56 There were significant differences between healthy and diabetic individuals flow velocities in OA (systolic $p<0.01$ and diastolic $\mathrm{p}<0.001$ ) and CRA (systolic $\mathrm{p}<0.001$ and diastolic $\mathrm{p}<0.001$ ) (Tables 2 and 3). At the proliferative stage, ocular blood flow velocity values were found to be lower than those recorded in normals. This reduction was statistically significant in the systolic, diastolic, and mean arterial velocities $(\mathrm{p}<0.05)$ (Table 4). Diabetic subjects showed a slight but not significant decrease in the systolic and diastolic venous velocities in the VV compared with the healthy volunteers. No significant differences were noted between male and female subjects. No significant correlations were found between age and blood velocities. Tables 2, 3 and 4 show the velocities obtained in diabetic and normal subjects.

\section{Discussion}

Colour Doppler imaging has made it possible to evaluate orbital blood flow under real time and physiological conditions. CDI incorporates the use of two dimensions B scan with colour Doppler. This technology allows the examination, with minimal discomfort and risk, of blood flow in the orbit. This cannot be done with $\mathbf{B}$ scan alone. The velocity of the blood flow in the ocular vessels can also be evaluated. ${ }^{5} 6$

Other methods measure different parts of the retinal circulation, and have been used for studying diabetic retinopathy. The blue light entoptic phenomenon ${ }^{78}$ allows determination of the perifoveal flow velocity of leucocytes. On the other hand, laser Doppler velocimetry measures the velocity of red blood cells in the main retinal vessels. ${ }^{910}$ Other techniques are two point fluorophotometry, ${ }^{1-13}$ photoangiography, ${ }^{14}$ and video fluorescein angiography which measure the time required for fluorescein to travel from an arteriole to the corresponding venule. ${ }^{15}$ Retinal and choroidal blood flow can also be determined using the radionuclide labelled microsphere technique in animals. ${ }^{16} 17$

The range of error seen in most studies 
reporting laser Doppler flow data is $18 \%$ (errors in interpreting the Doppler shifted frequency spectrum and in measuring the Doppler angle). ${ }^{18}$

The initial lesions of diabetic retinopathy affect capillaries, small arterioles, and venules. The earliest changes are retinal capillary bed obstructions and capillary dropout. Progressive thickening of the basement membrane narrows the lumen of capillaries; microaneurysms, venous abnormalities, arteriovenous shunts, and later neovascularisation develop. These changes of vessel morphology may disturb the retinal microcirculation. On the other hand, diabetes mellitus affects the blood rheology. Increased blood viscosity and plasma viscosity, 1920 increased red blood cell aggregation, ${ }^{21}{ }^{22}$ and increased platelet aggregation and change of platelet shape 2324 reduce the retinal blood flow if not compensated by regulatory mechanisms.

Some investigations suggest decreased retinal blood flow or increased retinal circulation times in PDR. ${ }^{711131425}$ On the contrary, Kohner et al showed normal values in severe retinopathy. ${ }^{26}$ In a study of Grunwald et al, using laser Doppler velocimetry, arterial and venous blood flow velocity was less than normal in background and proliferative retinopathy ${ }^{10}$; the calculated volumetric blood flow rate, however, did not differ from normal in all stages of retinopathy without retinal photocoagulation. Some authors reported, in a long term follow up study, that the perifoveolar blood velocity (measured by blue field entoptic phenomenon) decreased in the course of diabetic retinopathy. ${ }^{27} 28$ However, some studies showed that acute fluctuations in plasma glucose levels are not associated with changes of perifoveal blood flow. ${ }^{829}$ On the other hand, other authors reported that bad glycaemic control seems to worsen retinal microcirculation. ${ }^{13}$ This may be one cause of the increasing prevalence of ischaemic lesions and their vascular complications in patients with a long history of diabetes mellitus. Some investigators measured the transit time of fluorescein in the retina in prediabetic and diabetic patients and found it to be shorter than normal. ${ }^{30}$ They explain their findings by the presence of arteriovenous shunts in the retinal periphery in prediabetes. If such shunts existed they would cause diversion of blood from areas of the capillary beds, causing nonperfusion of large areas in early diabetes and mild retinopathy. Using laser Doppler velocimetry and computerised image analysis retinal blood flow was significantly increased in all grades of untreated diabetic retinopathy. ${ }^{31}$

Increased volume flow in other organs of diabetics has been reported. ${ }^{32} 34$ On the other hand, in capillaries of the conjunctiva bulbi ${ }^{35} 36$ and of the nailfold, ${ }^{37}$ a decreased blood velocity was also found in diabetics. Long standing diabetes in humans is associated with a decrease in the cerebral artery blood flow, attenuation of the cerebral vasodilator response to $5 \%$ carbon dioxide, and loss of global cerebral autoregulatory capacity.
Blood flow is directly dependent on vascular diameter. CDI cannot accurately assess the diameter of the vessels; for this reason, we could not conclude that blood flow was also decreased, but probably it occurs. Perhaps, the reduction of flow velocities might be associated with changes of the retinal blood flow, before more severe morphological changes. The reduction of capillary blood flow velocities and the increased diffusion times may lead to chronic hypoxia of the retinal tissues. ${ }^{38}$

In comparison with the healthy group, diabetics showed significant differences in arterial blood flow velocities apart from the CRV. No significant differences of venous velocities were observed between diabetic patients and normals, but diabetics showed a slight decrease in systolic and diastolic venous velocities except for the CRV (Tables 2 and 3 ). This feature could reflect arterial dilatation greater than venous (vascular diameter increases could be associated with lesser blood flow velocity and the same blood flow).

An endothelium derived relaxing factor is released tonically under physiological conditions, thereby influencing basal blood flow in healthy humans. It is possible that impaired endothial factor biosynthesis is generalised in such patients and contributes to the pathogenesis of overt vascular complications. ${ }^{39}$ Several of the actions of this factor on vascular smooth muscle and platelets make it plausible.

In conclusion, in diabetic patients with retinopathy findings on retinal blood flow are controversial. Both reduction and increase of retinal blood flow has been reported in all stages of diabetic retinopathy. In this study, we have found lower flow velocities in PDR patients than healthy volunteers, suggesting a low retinal perfusion, which might contribute to ischaemia of the choroidal and the inner retinal layers.

1 Engerman RL. Pathogenesis of diabetic retinopathy. Diabetes 1989; 38: 1203-6.

2 Glaser B. Extracellular modulating factors and the control of intraocular neovascularization. Arch Ophthalmol 1988; 106: 603-11.

3 Grant EG, Tessler FN, Perrella RR. Clinical Doppler imaging. Am $\mathcal{F}$ Radiol 1989; 52: 707-17.

4 Early Treatment Diabetic Retinopathy Study Research Group. Grading diabetic retinopathy from stereoscopic color fundus photographs: an extension of the modified Airlie house classification. Ophthalmology 1991; 98: 786-806.

5 Lieb WE, Cohen SM, Merton DA, Shields JA, Mitchell DG, Goldberg BB. Color Doppler imaging of the eye and orbit: technique and normal vascular anatomy. Arch Ophthalmol 1991; 109: 527-31.

6 Guthoff RF, Berger RW, Winkler P, Helmke K, Chumbley LC. Doppler ultrasonography of the ophthalmic and central retinal vessels. Arch Ophthalmol 1991; 109: 532-6.

7 Fallon TJ, Maxwell DL, Kohner EM. Autoregulation of retinal blood flow in diabetic retinopathy measured by the blue light entoptic phenomenon. Br $\mathcal{F}$ Ophthalmol 1987; 94: $1410-5$

8 Davies EG, Hyer SL, Kohner EM. Macular blood flow response to acute reduction of plasma glucose in diabetic patients measured by the blue light entoptic technique. Ophthalmology 1990; 97: 160-4.

9 Riva CE, Grunwald JE, Sinclair SH, Petrig BL. Blood velocity and volumetric flow rate in human retinal vessels. Invest Ophthalmol Vis Sci 1985; 26: 1124-32.

10 Grunwald JE, Riva CE, Sinclair SH, Brucker AJ, Petrig BL. Laser Doppler velocimetry study of retinal circulaBL. Laser Doppler velocimetry study of retinal circula-
tion in diabetes mellitus. Arch Ophthalmol 1986; 104: tion in

11 Cunha-Vaz JG, Fonseca JR, De Abreu JRF. Studies on retinal blood flow: II. Diabetic retinopathy. Arch Ophthalmol 1978; 96: 809. 
12 Oswald B, Vilser W, Oswald H, Jütte A, Königsdorfer E, Schweitzer D. Messung Strömungsphysiologischer Grössen der Netzhautzirkulation bei Diabetikern Typ 1 und 2. Graefes Arch Clin Exp Ophthalmol 1983; 220: 42-6.

13 Yoshida A, Feke GT, Morales-Stoppello J, Collas GD, Goger DG, MacMeel JW. Retinal blood flow alterations during progression of diabetic retinopathy. Arch during progression of dia

14 Koerner F, Fries K, Niesel P, Dubied P. Zur Interpretation der retinalen Kreislaufzeiten bei der diabetischen Retinopathie vor und nach Photokoagulation. Klin Monatsbl Augenheilkd 1978; 178: 440-4.

15 Sinclair SH, Grunwald JE, Riva CE, Braunstein SN, Nichols CW, Schwartz SS. Retinal vascular autoregulation in diabetes mellitus. Ophthalmology 1982; 89: 748-50.

16 Heymann MA, Payne BD, Hoffman JID, Rudolph AM. Blood flow measurements with radionuclide-labeled particle. Prog Cardiovasc Dis 1977; 20: 55-76.

17 Chemtob S, Beharry K, Rex J, Chatterjee T, Varma DR, Aranda JV. Ibuprofen enhances retinal and choroidal blood flow autoregulation in newborn piglets. Invest Ophthalmol Vis Sci 1991; 32: 1799-807.

18 Feke GT, Tagawa H, Deupree DM, Goger DG, Sebag J, Weiter JJ. Blood flow in the normal human retina. Invest Ophthalmol Vis Sci 1989; 30: 58-65.

19 Rimmer T, Fleming J, Kohner EM. Hypoxic viscosity and diabetic retinopathy. Br $\mathcal{f}$ Ophthalmol 1990; 74: 400-4.

20 Tillmann $W$, Lakomek $M$, Heidemann $P$, BehrensBaumann W, Schröter W. Aggregate formation of erythrocytes and diabetic retinopathy in children, adoleserythrocytes and diabetic retinopathy in children, adolescents and adults with diabet
Wochenschr 1984; 62: 1136-9.

21 Othmane A, Bitbol M, Snabre P, Mills P, Grimaldi A, Bosquet $F$. Red-cell aggregation in insulin-dependent diabetics. Clin Hemorheol 1989; 9: 281-95.

22 Porta $M$, Hilgard P, Kohner EM. Platelet shape change abnormalities in diabetic retinopathy. Diabetologia 1980; 18: 217-21.

23 Agardh CD, Agardh E, Bauer B. Platelet aggregation in type I diabetics with and without proliferative retinopathy. Acta Ophthalmol 1987; 65: 358-62.

24 Soeldner JS, Christacopoulos PD, Gleason RE. Mean retinal circulation times as determined by fluorescein retinal circulation times as determined by fluorescein angiography in normal prediabetic a

25 Blair NP, Feke GT, Morales-Stopello J. Prolongation of the retinal mean circulation time in diabetes. Arch Ophthalmol 1982; 100: 764-8.
26 Kohner EM, Hamilton AM, Saunders SJ, Sutcliffe BA, Bulpitt CJ. The retinal blood flow in diabetes. Diabetologia 1975; 11: 27-33.

27 Rimmer T, Fallon TJ, Kohner EM. Long-term follow-up of retinal blood flow in diabetes using the blue light entoptic phenomenon. Br $\mathcal{F}$ Ophthalmol 1989; 73: 1-5.

28 Bertram B, Wolf S, Fiehöfer S, Schulte K, Arend O, Reim M. Retinal circulation times in diabetes mellitus type 1. Br F Ophthalmol 1991; 75: 462-5.

29 Fallon TJ, Sleightholm MA, Merrick C, Chahal P, Kohner EM. The effect of acute hyperglycemia on flow velocity in the macular capillaries. Invest Ophthalmol Vis Sci 1987; 28: 1027-30

30 Christocopoulos PD, Soeldner JS, Gleason RE. Variation in retinal haemodynamics in different stages of diabetes. Excerpta Med 1973; 280: 180-1.

31 Patel V, Rassam S, Newsom R, Wiek J, Kohner E. Retinal blood flow in diabetic retinopathy. $B M F$ 1992; 305: 678-83.

32 Butterfield WH, Wichelow MS. Peripheral glucose metabolism in control subjects and diabetic patients during glucose, glucose-insulin and insulin sensitivity tests. Diabetologia 1965; 1: 45-53.

33 Alexander K, Teusen R, Mitzkat HJ. Vergleichende Messungen der Extremitätdurchblutung bei Diabetikern und Stoffwechselgesunden. Klin Wochenschr 1968; 46: 234-8.

34 Christensen NJ. A reversible vascular abnormality associated with diabetic Ketosis. Clin Sci 1970; 39: 539.

35 Körber N, Wolf S, Kranemann C, Lück M. Quantitative konjunctivale Videokapillaroskopie in der Diagnostik von Mikrozirkulationsstörungen. Sitzungsbericht der 148 . Mersammlung des Vereins Rheinisch-Westfälischer Augenärzte Versammlung

36 Ditzel J, Saglid U. Morphologic and hemodynamic changes in the bulbar conjunctiva of normotensive diabetic patients. N Engl f Med 1954; 250: 587-94.

37 Fagrel B, Hermansson IL, Karlander SG, Ostergren J. Vita capillary microscopy for assessment of skin viability and microangiopathy in patients with diabetes mellitus. Med Scand 1984; 687: 25-8.

38 Arend $\mathrm{O}$, Wolf $\mathrm{S}$, Jung $\mathrm{F}$, Bertram $B$, Pöstgens $H$, Toonen H, Reim M. Retinal microcirculation in patients with diabetes mellitus: dynamic and morphological analysis of diabetes mellitus: dynamic and morphological analysis of perifove

39 Mayhan WG. Impairment of endothelium-independent dilatation of cerebral arterioles during diabetes mellitus. Am $\mathcal{F}$ Physiol 1989; 256: 621-5. 